\title{
Intrapartum HIV Screening Revisited. Which Approach is Appropriate for Sub - Saharan Africa Today: Opt-in, Opt-out or both?
}

Luchuo Engelbert Bain ${ }^{1}$ and Elvis Enowbeyang Tarkang ${ }^{2^{*}}$

${ }^{1}$ Department of Military Health, Ministry of Defense, Cameroon

${ }^{2}$ HIVIAIDS Prevention Research Network, Cameroon (HIVPREC) P. O. Box 36, Commonwealth Avenue, Kumba, Cameroon

*Corresponding author: Elvis Enowbeyang Tarkang, HIVIAIDS Prevention Research Network, Cameroon (HIVPREC) P. O. Box 36, Commonwealth Avenue, Kumba, Cameroon; Tel: 237-33354369, 237-33354024; E-mail: ebeyang1@yahoo.com

Received date: August 17, 2014; Accepted date: October 24, 2014; Published date: October 27, 2014

Copyright: () 2014 Bain LE, et al. This is an open-access article distributed under the terms of the Creative Commons Attribution License, which permits unrestricted use, distribution, and reproduction in any medium, provided the original author and source are credited.

\begin{abstract}
Background: Prevention of mother-to-child transmission of the Human Immuno Virus (HIV) remains an opportunity not to be missed in case future remarkable declines in HIV associated morbidity and mortality are envisaged. Many pregnant women, both in the developed and developing countries today are still received in labor rooms with unknown or redoubtable HIV serostatus. Ethical tensions arising from compulsory (opt in) or consenting (opt out) strategies regarding the labor room HIV testing remain unresolved.
\end{abstract}

Conclusion: This paper presents some neglected and potentially useful avenues that could be exploited especially in high HIV prevalence settings like Sub-Saharan Africa. The authors also highlight key areas for future research.

Keywords: HIV screening and testing; Intrapartum; Africa; Opt-in; Opt-out

\section{Background}

Despite indisputable evidence with respect to the effectiveness of Anti-Retroviral Therapy (ART) in reducing viral replication and mother-to-child transmission of the Human Immunodeficiency Virus (HIV), many women still give birth without either being offered the possibility to get tested, or deliberately refuse to get tested for personal reasons $[1,2]$. About $95 \%$ of the 3.2 Million children affected with HIV worldwide are infected during the intrapartum period [3]. One thirds (32\%) of pregnant women in developing countries give birth with no previous antenatal care [4]. In 2003, only $53 \%$ of pregnant women living with HIV in Sub-Saharan Africa had received Anti Retroviral Therapy for the Prevention of Mother to Child Transmission [5].

It might be important to note however that the state of pregnancy, and especially labor, is associated with a serious emotional distress and anxiety, and might not be the best of moments to convince clients to accept to take an HIV test. Testing HIV negative at the beginning or at some point in time early in pregnancy is not a guarantee the patient shall remain so till the end. It might be worth noting that we are dealing with a developing country setting with generally high HIV prevalence, whose transmission is heterosexual. It is not rare to have new infections during pregnancy. The timing and quality of an HIV test remains crucial in diagnosing new infections. Early infections, tested in the window phase of the infections might be missed if the test is not repeated later, or at best later in the pregnancy course. Most HIV tests offered in Sub-Saharan African contexts are serologic (detect mainly antibodies) rather than are antigen detecting. With prenatal care not at its optimum in these settings therefore, the intrapartum period therefore still remains an opportunity to detect some missed cases of HIV positive mothers, where we can intervene appropriately to reduce mother-to-child transmission of the virus. Increasing prenatal, and if possible, pre-conception HIV testing however remain the key action areas, in case any appreciable reductions in HIV transmission from the mother to the child are envisaged. Most pregnancies, especially teenage pregnancies are unplanned. Making pre-conception counselling and testing the rule in most settings however remains difficult to achieve.

\section{Discussion}

Tensions with regards to the rights of a pregnant woman to determine what is done to her body (autonomy) and obligations to the well-being of an unborn child (beneficence) remain unresolved. The ethical dilemma with regards to the HIV-screening and testing approach to be adopted (opt-in or opt-out) in high HIV prevalence settings persists. The potential impact for intrapartum interventions are greatest for those women who recently have seroconverted and those with unknown HIV status [5,6].

In a recent study from four African countries (Burkina Faso, Kenya, Malawi and Uganda), clients were retrospectively asked concerning the issue of consent to HIV tests. Over $77 \%$ of them reported they could not have refused [7]. Doing a mandatory HIV test on its own is no guarantee of being adherent to treatment. Post-partum adherence rates to ART have been found to be significantly lower than antenatal compliance rates in a recent meta-analysis [8]. In Cameroon, acceptability of intrapartum HIV testing is high, with an accompanying high HIV prevalence. Kongyuy et al report over $88 \%$ of women accepting labor room testing and an HIV prevalence of $10 \%$ amongst these women [9].

Proper psychosocial preparation and allowing clients to willfully accept to get tested could increase posttest compliance to treatment $[1,4]$. Psychosocial support staffs with regard to HIV care are rare and almost inexistent in most clinical settings in resource limited countries. Persistent issues with regard to perceived severity of HIV/ 
Citation: Bain LE, Tarkang EE (2014) Intrapartum HIV Screening Revisited. Which Approach is Appropriate for Sub - Saharan Africa Today: Opt-in, Opt-out or both?. J AIDS Clin Res 5: 363. doi:10.4172/2155-6113.1000363

Page 2 of 2

AIDS (Human Immuno Virus/Acquired Immune Deficiency Syndrome) could explain to some extent why some women could still refuse getting tested. The place of a man in most African settings places the decision at times to comply with certain female related health concerns difficult. Uptake of HIV screening and care could be improved if the male factor is included [10]. Most of the rare community health workers that received training in this domain go for several months without salary. It is urgent for actors within the health care system to recognize the inadequacy of human resources with regard to psychosocial support within the fight against HIV in Africa as a priority. Involvement of men in the prevention of mother-to-child HIV transmission activities could be potentially beneficial. Feasibility studies with regard to this are however required. An ethically sound decision in this context could require deep reflections upon the sociocultural peculiarities of the various ethnic representations.

\section{Conclusion}

Reinforcing counseling and routine prenatal HIV testing is imperative. Little is known regarding why some women turn down HIV screening in Sub-Saharan Africa. Qualitative research exploring insights that could explain this could be of interest to public health actors. The psychosocial components of healthcare are key determinants of compliance to treatment after testing. Getting an HIV test done is not an equivalent of being fully compliant to management guidelines. Training of competent staff to manage the crucial psychosocial components in stigmatizing conditions like HIV/AIDS must be considered an emergency by policy makers and effectively acted upon.

\section{Competing Interests}

The authors declare no competing interests.

\section{Authors' contributions}

LEB conceived and wrote the manuscript; EET provided intellectual content and revised several versions of the manuscript. Both authors read and approved the final manuscript.

\section{References}

1. Maartens G, Celum C, Lewin SR (2014) HIV infection: epidemiology, pathogenesis, treatment, and prevention. Lancet 384: 258-271.

2. Siegfried N, van der Merwe L, Brocklehurst P, Sint TT (2011) Antiretrovirals for reducing the risk of mother-to-child transmission of HIV infection. Cochrane Database Syst Rev : CD003510.

3. Williams DW, Eugenin EA, Calderon TM, Berman JW (2012) Monocyte maturation, HIV susceptibility, and transmigration across the blood brain barrier are critical in HIV neuropathogenesis. J Leukoc Biol 91: 401-415.

4. Minkoff $\mathrm{H}$ (2001) Prevention of mother-to-child transmission of HIV. Clin Obstet Gynecol 44: 210-225.

5. World Health Organisation (2003) Antenatal Care in developing countries: promises, challenges and missed opportunities. Geneva.

6. Liu KC, Chibwesha CJ (2013) Intrapartum management for prevention of mother-to-child transmission of HIV in resource-limited settings: a review of the literature. Afr J Reprod Health 17: 107-117.

7. Obermeyer CM, Verhulst C, Asmar K; MATCH study group (2014) Could you have said no? A mixed-methods investigation of consent to HIV tests in four African countries. J Int AIDS Soc 17: 18898.

8. Nachega JB, Uthman OA, Anderson J, Peltzer K, Wampold S, et al. (2012) Adherence to antiretroviral therapy during and after pregnancy in low-income, middle-income, and high-income countries: a systematic review and meta-analysis. AIDS 26: 2039-2052.

9. Kongnyuy EJ, Mbu ER, Mbopi-Keou FX, Fomulu N, Nana PN, et al. (2009) Acceptability of intrapartum HIV counselling and testing in Cameroon. BMC Pregnancy Childbirth 9: 9.

10. Wettstein C, Mugglin C, Egger M, Blaser N, Vizcaya LS, et al. (2012) Missed opportunities to prevent mother-to-child-transmission: systematic review and meta-analysis. AIDS 26: 2361-2373. 